Jurnal Ilmiah Ibnu Sina, 6(2), Oktober 2021, 161-167

p-ISSN: 2502-647X; e-ISSN: 2503-1902

\title{
STUDI TINGKAT PENGETAHUAN DAN PERSEPSI TENAGA KESEHATAN MENGENAI PERANAN FARMAKOGENOMIK
}

\author{
Muhammad Akib Yuswar*, Robiyanto, Eka Kartika Untari, \\ Shoma Rizkifani \\ Jurusan Farmasi, Fakultas Kedokteran, Universitas Tanjungpura Pontianak ${ }^{1}$ \\ *Email: akib.yuswar@pharm.untan.ac.id
}

Artikel diterima: 03 Desember 2020; Disetujui: 03 Oktober 2021

DOI: https://doi.org/10.36387/jiis.v6i2.640

\begin{abstract}
ABSTRAK
Penelitian tentang sejauh mana pemahaman petugas kesehatan di Kalimantan Barat akan pentingnya peran farmakogenomik hingga saat ini belum pernah dilaporkan. Kalimantan Barat (Kalbar) dikenal sebagai provinsi bercirikan tiga etnis utama yaitu Tionghoa, Melayu, dan Dayak. Karena itu, potensi penerapan farmakogenomik bagi pengobatan pasien di fasilitas-fasilitas kesehatan yang tersebar di provinsi ini sangat memungkinkan. Penelitian ini bertujuan untuk mengukur tingkat pengetahuan dan persepsi dari para praktisi kesehatan (partisipan) tentang peranan farmakogenomik terhadap rencana pengobatan pasien. Penelitian ini bersifat deskriptif menggunakan metode survey. Data penelitian yang dianalisis merupakan data primer dari jawaban partisipan atas kuesioner online. Berdasarkan 106 respons partisipan yang meliputi dokter, apoteker, ners, bidan, dan lainnya, yang berasal dari berbagai kota dan kabupaten, diketahui tingkat pengetahuan di level sangat baik (75.5\%), baik (17.0\%), dan kurang baik (7.5\%). Tingkat persepsi partisipan terhadap peranan farmakogenomik yaitu memiliki persepsi positif (97.2\%) dan persepsi negatif (2.8\%). Secara umum, diambil kesimpulan bahwa tenaga kesehatan di Kalimantan Barat memiliki tingkat pengetahuan yang sangat baik dan persepsi positif tentang pentingnya peran farmakogenomik.
\end{abstract}

Kata kunci: pengetahuan, persepsi, farmakogenomik, tenaga kesehatan, Kalimantan Barat.

ABSTRACT

Research on the extent to which health practitioners in West Kalimantan understand the important role of pharmacogenomics have not been reported to date. West Kalimantan (Kalbar) is known as a province characterized by three main ethnicities, namely Chinese, Malay and Dayak. Therefore, the potential application of pharmacogenomics for the treatment of patients in health facilities across the province is very possible. This study aimed to measure the level of knowledge and perceptions of health practitioners (participants) about the role of pharmacogenomics in patient treatment plans. This research is descriptive with a questionnaire-based survey method. The data analyzed is primary data from the answers of participants to the online questionnaire. Based on the responses of 106 
Jurnal Ilmiah Ibnu Sina, 6(2), Oktober 2021, 161-167

p-ISSN: 2502-647X; e-ISSN: 2503-1902

participants (involving doctors, pharmacists, nurses, midwives, and others) from various cities and districts in West Kalimantan, it was found that the level of knowledge was very good (75.5\%), good (17.0\%), and not good. (7.5\%). The level of participants' perceptions of the role of pharmacogenomics are those who have positive perceptions (97.2\%) and negative perceptions (2.8\%). It can be concluded that $75 \%$ of health practitioners in West Kalimantan have a very good level of knowledge and $97 \%$ of them own a positive perception of the importance of pharmacogenomics.

Keywords: knowledge, perception, pharmacogenomics, health practitioners, West Kalimantan

\section{PENDAHULUAN}

Implementasi farmakogenomik di Indonesia sendiri masih sangat jarang terdengar. Hal ini bukan karena bidang ilmu ini tergolong baru melainkan adanya tantangan berupa persiapan maksimal dari sisi pengetahuan praktisi klinis maupun tersedianya infrastruktur teknologi untuk mengelola big data berupa electronic health record (Conti, et al., 2010). Tenaga kesehatan perlu menyadari akan pentingnya peran farmakogenetik untuk diaplikasikan dalam pengobatan personalisasi sehingga interaksi kesesuaian antara genetika pasien dengan terapi obat yang diterima pasien dapat dioptimalkan dan dirancang sejak awal pengobatan.

Manfaat farmakogenomik mulai digaungkan lebih dari satu dekade silam setelah sekuen lengkap genom manusia selesai. Farmakogenomik telah menciptakan kemajuan berarti sebagai dasar ilmiah untuk meningkatkan keamanan obat dan optimalisasi efek terapi obat (Ang, et al., 2017). Namun sayangnya, farmakogenomik belum banyak dipraktikkan di institusi atau fasilitas kesehatan masyarakat di negaranegara Asia, salah satunya di Indonesia. Pihak-pihak yang mendukung praktik farmakogenomik berkeyakinan bahwa kasus efek samping obat yang tidak diinginkan, bahkan resiko kematian dapat dibatasi sehingga pasien akan mendapat kesempatan sembuh lebih tinggi untuk penyakit-penyakit seperti kanker, gangguan darah dan kardiovaskular, neurologis, psikiatri, bahkan penyakit gangguan metabolism (Ang, et al., 2017; Conti, et al., 2010). Tes farmakogenomik dapat membantu 
Jurnal Ilmiah Ibnu Sina, 6(2), Oktober 2021, 161-167

p-ISSN: 2502-647X; e-ISSN: 2503-1902

menemukan jenis dan regimen terapi obat yang lebih optimal berdasarkan genetika pasien dalam waktu yang relatif singkat. Pada prinsipnya pasien akan diminta memberikan sampel swab liur untuk diperiksa di laboratorium agar bisa diketahui apakah gen pasien tersebut sesuai atau berhubungan dengan efek farmakologis obat yang diinginkan oleh dokter (Global News, 2019). Singkatnya, kemungkinan identifikasi kerentanan seseorang terhadap penyakit tertentu dan respons positif pasien terhadap terapi obat yang direncanakan menjadi tujuan utama dari farmakogenomik yang memang memiliki fokus pengobatan berdasarkan karakteristik genetik dari masing-masing pasien (Tremblay dan Hamet, 2013; Di Sanzo, et al., 2017).

Seiring waktu, pola peresepan obat berdasarkan gejala, usia, berat badan mungkin satu atau dua dekade lagi akan digeser menjadi pola pengobatan berdasarkan genetika masing-masing individu (Global News, 2019). Konsep pengobatan individu akan menjadi kunci sukses pengobatan yang mungkin dapat menyelamatkan nyawa pasien jika para pemangku kebijakan mempersiapkan aspek-aspek pendukungnya semaksimal mungkin, salah satunya adalah aspek edukasi. Dengan mengangkat tema penelitian farmakogenomik diharapkan pengetahuan dan kesadaran masyarakat yang terlibat dalam penelitian ini akan bertambah.

Adapun tujuan dari penelitian adalah yaitu untuk mengukur pengetahuan tenaga kesehatan tentang bidang ilmu farmakogenomik. Kemudian menilai persepsi dan sikap tenaga kesehatan mengenai manfaat farmakogenomik terhadap rencana pengobatan pasien.

\section{METODE PENELITIAN}

Penelitian ini bertujuan untuk mengukur dan menilai tingkat pengetahuan dan persepsi tenaga kesehatan terhadap ilmu farmakogenomik dan peranan farmakogenomik dalam penentuan terapi pada pasien. Penelitian ini merupakan penelitian survey analitik dengan desain potong lintang. Data yang diambil merupakan data primer yang berasal isian atau jawaban partisipan pada kuesioner. Kuesioner 
Jurnal Ilmiah Ibnu Sina, 6(2), Oktober 2021, 161-167

p-ISSN: 2502-647X; e-ISSN: 2503-1902

yang digunakan diadopsi dari jurnal "Knowledge, Attitudes And Education Of Pharmacists Regarding Pharmacogenetic Testing" yang terdiri dari 31 pertanyaan yang menggambarkan tingkat pengetahuan dan persepsi mengenai farmakogenomik pada partisipan. Kuesioner akan diberikan melalui google form atau secara online satu kali setiap partisipan. Survei ini bersifat sukarela dan tidak ada paksaan pada calon partisipan, oleh karena itu sebelum penelitian dimulai protokol penelitian harus telah lolos kaji etik.

Populasi adalah wilayah generalisasi yang terdiri atas objek/ partisipan yang mempunyai kualitas dan karakteristik tertentu yang ditetapkan oleh peneliti untuk dipelajari dan kemudian dapat ditarik kesimpulannya (Murti, 2007). Populasi dalam penelitian ini adalah seluruh tenaga kesehatan di Kalimantan Barat. Sampel ataupun partisipan yang merupakan subset yang dicuplik dari populasi, yang akan diamati atau diukur peneliti. Pemilihan partisipan dalam penelitian ini menggunakan teknik sampling non prababilitas purposive sampling hingga kuota atau jumlah sampel yang diinginkan terpenuhi (Sullivan, 2003). Berdasarkan rumus perhitungan sampel maka diperoleh jumlah minimal sampel yaitu 105 .

Pada kuesioner terdapat 16 pertanyaan, yang dibagi menjadi 2 bagian yaitu bagian pengetahuan sebanyak 8 pertanyaan dan bagian persepsi sebanyak 8 pertanyaan. Serta bagian awal untuk mengetahui karakteristik sampel.

Kriteria inklusi dari populasi penelitian ini yaitu:

1. Partisipan adalah tenaga kesehatan yaitu: dokter/apoteker/ners yang bekerja di wilayah Kalimantan Barat

2. Berusia dewasa 23-65 tahun

3. Bersedia menjadi partisipan penelitian

Analisis data bersifat deskriptif dan tabulasi. Perhitungan skoring dilakukan dari hasil jawaban kuesioner yang diberikan kepada responding. Nilai jawaban kuesioner selanjutnya dikelompokkan kepada kriteria pengetahuan dan persepsi.

\section{HASIL DAN PEMBAHASAN}

Pada tahapan pertama dalam 
Jurnal Ilmiah Ibnu Sina, 6(2), Oktober 2021, 161-167

p-ISSN: 2502-647X; e-ISSN: 2503-1902

penelitian ini yaitu melakukan uji validitas dan reliabilitas pada kuesioner yang telah dibuat, dimana kuesioner mengacu pada penelitian yang dilakukan oleh Roederer, dkk pada tahun 2012. Berdasarkan hasil uji menyatakan bahwa kuesioner yang dibuat telah valid dan reliabel, sehingga dapat digunakan untuk penelitian selanjutnya.

Tabel 1. Karakteristik Partisipan

\begin{tabular}{|c|c|c|c|}
\hline \multicolumn{2}{|c|}{ Karakteristik } & \multirow{2}{*}{$\begin{array}{c}\mathbf{N} \\
29\end{array}$} & \multirow[t]{2}{*}{$\%$} \\
\hline Usia & $\begin{array}{l}\text { Rerata } \\
\text { (tahun) }\end{array}$ & & \\
\hline \multirow{3}{*}{$\begin{array}{l}\text { Jenis } \\
\text { kelamin }\end{array}$} & Laki-laki & 40 & 37,7 \\
\hline & Perempuan & 66 & 62,3 \\
\hline & Dokter & 12 & 11,3 \\
\hline \multirow[t]{5}{*}{ Profesi } & Apoteker & 49 & 46,2 \\
\hline & ners & 21 & 19,8 \\
\hline & Bidan & 6 & 5,7 \\
\hline & Lainnya & 18 & 17,0 \\
\hline & $0-4$ tahun & 59 & 55,7 \\
\hline \multirow{4}{*}{$\begin{array}{l}\text { Lama } \\
\text { berpraktek }\end{array}$} & $5-10$ tahun & 33 & 31,1 \\
\hline & 11 - 19 tahun & 12 & 11,3 \\
\hline & 20 - 29 tahun & 1 & 0,9 \\
\hline & $>30$ tahun & 1 & 0,9 \\
\hline \multirow{4}{*}{$\begin{array}{l}\text { Jenis } \\
\text { pendidikan } \\
\text { atau } \\
\text { wawasan } \\
\text { ilmu } \\
\text { genetika } \\
\text { yang anda } \\
\text { miliki? }\end{array}$} & $\begin{array}{l}\text { saat } \\
\text { perkuliahan }\end{array}$ & 91 & 85,8 \\
\hline & $\begin{array}{l}\text { tidak } \\
\text { memiliki } \\
\text { wawasan } \\
\text { tentang ilmu } \\
\text { genetika }\end{array}$ & 10 & 9,4 \\
\hline & $\begin{array}{l}\text { melalui } \\
\text { seminar }\end{array}$ & 4 & 3,8 \\
\hline & lainnya & 1 & 0,9 \\
\hline
\end{tabular}

Setelah dilakukan pengambilan data, terdapat 106 sampel yang masuk kriteria inklusi yang telah melakukan pengisian kuesioner dengan lengkap dan jelas. Hasil dari kuesioner selanjutnya diolah lebih lanjut dalam bentuk tabel untuk mengetahui persebaran jawaban dari sampel.

Pada tabel 1 mencantumkan kriteria dari sampel yang meliputi usia, jenis kelamin, profesi, lama berpraktik, dan dari mana mengetahui tentang farmakogenomik sebelumnya.

Berdasarkan tabel 1 di atas diperoleh jumlah sampel sebanyak 106 orang dengan rerata usia yaitu 29 tahun. Jenis kelamin terbanyak yaitu perempuan $(62,3 \%)$, kemudian profesi meliputi dokter (11,3\%), apoteker (46,2\%), ners $(19,8 \%)$, dan bidan $(5,7 \%)$. Pada bagian lama berpraktek, yaitu 0-4 tahun (55,7\%), 5-10 tahun $(31,1 \%)$, dan 11-19 tahun (11,3\%). Kemudian pada bagian wawasan tentang genetika sebagian besar sampel mendapatkan ilmu tersebut pada saat perkuliahan.

Pada tabel 2 membahas tentang tingkat pengetahuan tenaga kesehatan mengenai farmakogenomik. Dari 106 sampel yang meliputi berbagai profesi yaitu dokter, apoteker, ners, bidan, dan 
Jurnal Ilmiah Ibnu Sina, 6(2), Oktober 2021, 161-167

p-ISSN: 2502-647X; e-ISSN: 2503-1902

lainnya, sebagian besar memiliki pertanyaan tes farmakogenomik dapat tingkat pengetahuan yang sangat baik, membantu menurunkan jumlah hal ini disebabkan dengan mudahnya kejadian efek samping obat yang tidak akses teknologi yang berimplikasi pada akses informasi yang didapat oleh tenaga kesehatan. Selain itu juga dengan adanya penelitian farmakogenomik di beberapa kota besar di Indonesia dinilai memegang peranan penting dalam hal personalisasi proses terapi bagi individu.

Tabel 2. Tingkat pengetahuan

\begin{tabular}{lccc}
\hline Kategori & \multicolumn{3}{c}{ Pengetahuan N $(\%)$} \\
& $\begin{array}{c}\text { Sangat } \\
\text { baik }\end{array}$ & Baik & $\begin{array}{c}\text { Cukup } \\
\text { Baik }\end{array}$ \\
\hline dokter & 11 & 1 & 0 \\
& $(10,4 \%)$ & $(0,9 \%)$ & \\
apoteker & 40 & 7 & $2(1,9 \%)$ \\
& $(37,8 \%)$ & $(6,6 \%)$ & \\
ners & 14 & 5 & $2(1,9 \%)$ \\
& $(13,2 \%)$ & $(4,7 \%)$ & \\
bidan & $2(1,8 \%)$ & 2 & $2(1,9 \%)$ \\
& & $(1,9 \%)$ & \\
lainnya & 13 & 3 & $2(1,9 \%)$ \\
& $(12,3 \%)$ & $(2,8 \%)$ & \\
& 80 & 18 & $8(7,5 \%)$ \\
& $(75,5 \%)$ & $(17 \%)$ & \\
\hline
\end{tabular}

Pada tabel 3, memperlihatkan data mengenai tingkat persepsi tenaga Kesehatan terhadap farmakogenomik. Terlihat bahwa Sebagian besar tenaga Kesehatan memiliki persepsi positif mengenai farmakogenomik.

Hal-hal yang dirasa positif oleh tenaga Kesehatan diantaranya pada

\section{UCAPAN TERIMA KASIH}

Terima kasih kepada DIPA UNTAN yang telah membiayai penelitian ini.

\section{DAFTAR PUSTAKA}

Global News. 2019, Farmakogenetika: masa depan 
Jurnal Ilmiah Ibnu Sina, 6(2), Oktober 2021, 161-167

p-ISSN: 2502-647X; e-ISSN: 2503-1902

pengobatan. Gakken Indonesia.

Tanggal akses 15 April 2020.

(https://gakken-

idn.id/articles/farmakogenetika-

masa-depan-pengobatan)

Ang, H. X., Chan, S. L., Sani, L. L., et al. 2017, Pharmacogenomics in Asia: a systematic review on current trends and novel discoveries.

Pharmacogenomics, vol. $\mathbf{1 8}$, no.9, hh. 891-910. Available at: http://dx.doi.org/10.2217/pgs2017-0009.

Conti, R., Veenstra, D. L., Armstrong, K., Lesko, L. J., Grosse, S. D. 2010, Personalized medicine and genomics: challenges and opportunities in assessing effectiveness, costeffectiveness, and future research priorities. Med. Decis. Making, vol. 30, no. 3, hh. 328340.

Di Sanzo, M., Cipolloni, L., Borro, M., et al. 2017, Clinical applications of personalized medicine: a new Paradigm and challenge. Curr Pharm Biotechnol. vol. 18, no. 3, hh. 194-203. Available at: http://dx.doi.org/10.2174/13892 01018666170224105600.

Tremblay, J., Hamet, P. 2013, Role of genomics on the path to personalized medicine. Metabolism, vol. 62(Suppl1), hh. S2-5

Murti, B. 2007, Populasi, sampel, dan pemilihan subyek. In: Naskah Tutorial (Pengembangan Bahan Pengajaran). Universitas Sebelas Maret. Solo. hh. 1-26.

Roederer, M. W., Van Riper, M., Valgus. J., Knafl, G., McLeod, H., 2012, Knowledge, attitudes and education of pharmacists regarding pharmacogenetic testing. Personalized Medicine (2012) 9(1), 19-27. Future Medicine Ltd 